RISKANTER BMI

\title{
Schlanke haben die höchste postoperative Mortalität
}

Das Sterberisiko nach einer Operation wird vom BMI der Patienten beeinflusst. Allerdings sind nicht stark Übergewichtige, sondern eher besonders Schlanke gefährdet. Für 189533 Patienten lagen in einer Datenbank des American College of Surgeons Angaben zu BMI, Eingriff und Sterberisiko vor. Ihre 30-Tage-Mortalität betrug 1,7\% ( $\mathrm{n}=$ 3245). In der Quintile mit dem niedrigsten BMI $(<23,1)$ gab es innerhalb von 30 Tagen fast doppelt so viele Todesfälle (1073 vs.
562) wie in der mittleren BMI-Quintile $(26,3-29,6)$. Selbst nach Berücksichtigung des operations- und patientenspezifischen Sterberisikos hatten die schlanksten Patienten eine um $40 \%$ höhere Odds Ratio bei der 30-Tage-Mortalität. Schlechtere Überlebenschancen hatten Dickere allerdings z. B. bei kolorektalen Resektionen, Cholezystektomien, Hernien-Ops oder Mastektomien.

Arch Surg 2011; published online Nov. 29/2011; doi: 10.1001/archsurg.2011.310

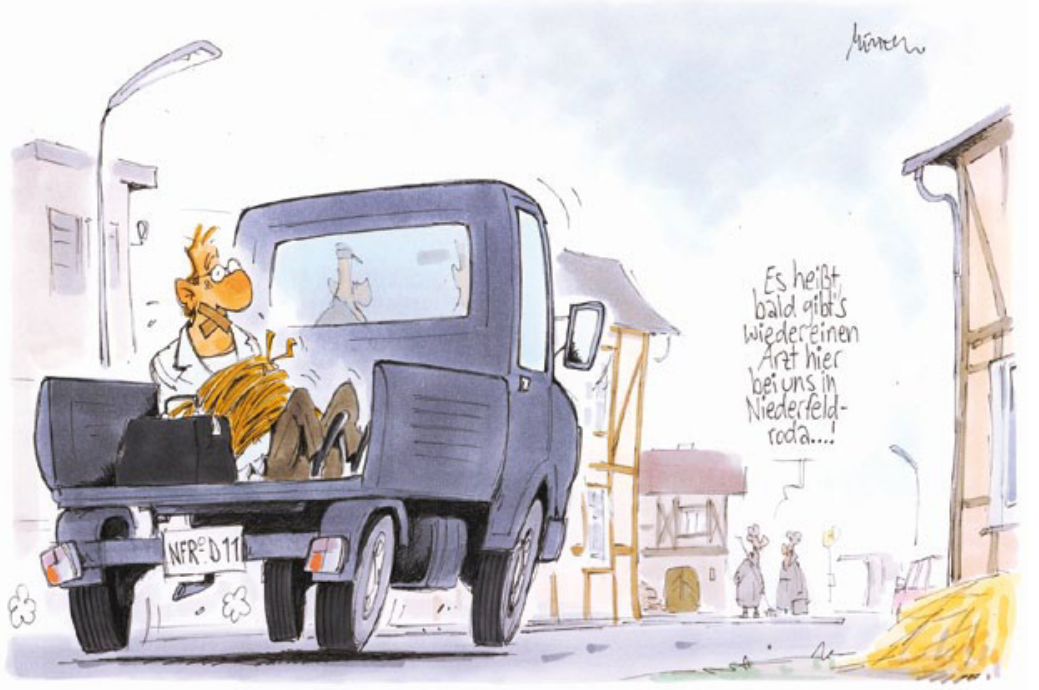

\section{TYPISCHES SCHMERZGESICHT}

\section{Brauen tief, Nase kraus}

Aus den Gesichtszügen eines Schmerzgeplagten kann man Rückschlüsse auf die Qualität der Schmerzempfindung ziehen. Augen zusammenkneifen heißt: Ich spüre körperlichen Schmerz. Nase kräuseln: Ich fühle mich emotional unwohl.

Miriam Kunz von der Universität Bamberg und ihre Kollegen piesackten 22 gesunde Freiwillige mit Hitzereizen aus einem Thermostimulator am Unterschenkel. Die sensorische Komponente der Schmerzempfin-

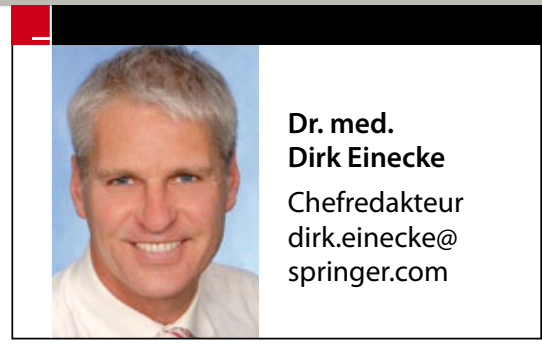

\section{Liebe Leserinnen, liebe Leser,}

im nächsten Jahr wird die MMW ihre Erscheinungsweise umstellen und in gedruckter Form in 14-tägigem Rhythmus erscheinen. Die einzelnen Hefte werden umfangreicher und eine größere Themenvielfalt bieten - in gewohnter MMW-Qualität.

Zusätzlich erweitern wir kontinuierlich unser Online-Angebot mit vertiefenden Informationen zu Beiträgen aus der MMW. In Planung sind darüber hinaus eine Online-Sprechstunde sowie eine MMW-App mit digitalen Angeboten für den Arzt unterwegs.

Auf dem großen Portal von SpringerMedizin (www.springermedizin.de), in das u.a. auch die Inhalte der MMWRedaktion einfließen, finden Sie ausführliche Dossiers, Diskussionsforen und Expertenräte zu einer Vielzahl praxisrelevanter Themen. Regelmäßig erscheinende Newsletter informieren online und komplementär zu den gedruckten Ausgaben der MMW über den neuesten Stand der Dinge.

All dies bedeutet für Sie ein Mehr an Fortbildung und noch aktuellere Informationen, die Ihnen in der täglichen Praxis von Nutzen sein können. Mit der crossmedialen MMW - in print und online - bleiben Sie up to date! Sichern Sie sich den regelmäßigen Bezug der MMW und viele weitere Vorteile wie z.B. das umfangreiche MMW-Archiv oder MMW-E-Paper für 99,- Euro jährlich (plus 39,- Euro Versandkosten) unter www.frankniemann.de. 